\title{
The Result Of Accounting Malfeasance In The Workplace: An Examination Of The Costs And Benefits Related To Job Satisfaction And Actively Managing The Organizational Ethical Work Climate \\ Mary Ellen Harvey, (mogrady@ramapo.edu), Ramapo College of New Jersey
}

\begin{abstract}
Many years of public airing of accounting ethical scandals resulted in organizations realizing the need to pro-actively engage available resources to influence the corporate ethical environment. Research attempting to measure the benefit of influencing and managing organizational ethics is important because establishing ethical programs in the workplace is time consuming and expensive. One such potential benefit is increased job satisfaction, which research has linked to reduced voluntary employee turnover. This type of turnover is generally considered undesirable and costly for organizations because of increased hiring and training expenses, and reduced customer satisfaction. Several prior studies have explored the relationship between job satisfaction and organizational ethical constructs. The study presented in this paper expands on this prior research, and found statistical evidence that managers can influence employee job satisfaction based on the ethical policies they choose to implement.
\end{abstract}

\section{INTRODUCTION}

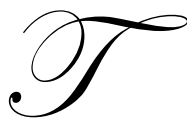

he headline news on March 21, 2006 included a story stating that over half of all workers in the United States are either looking for a new job, or would be willing to leave, given the right offer. And apparently the right offer must include more than just financial compensation for employees to feel satisfied enough in their position to stay put. At the same time, years of headline news has also covered the many accounting ethical scandals and resulting stream of bankruptcies and lawsuits. Employees and stakeholders throughout the world became critically aware of the damage that could result from ethical malfeasance in the workplace.

Clearly, both employee turnover and employee ethical behavior are contemporary and problematic concerns for organizations and their business managers. There is a genuine need to identify and employ strategies to control both these pragmatic workplace issues. The study presented in this paper, statistically identified a link between the two issues. Specifically, there is strong evidence that organizations that provide employee ethical training have more satisfied employees. Having a Code of ethics alone is not enough. The study also found statistical linkages between job satisfaction and specific types of corporate ethical environments, or "climates". Employees working in an environment where they perceive corporate self-interest, indicate they are less satisfied with their jobs. Finally, the study determined that whatever type of ethical environment exists in an organization, when employees are more aware of it, they are more satisfied. 


\section{BACKGROUND}

Job satisfaction research is important because of the relationship between voluntary employee turnover and job satisfaction. While this connection is somewhat intuitive, several key studies have also established it statistically (Larwood et al., 1998; Eby et al., 1999; Herndon et al., 2001). Even though managers acknowledge that turnover can sometimes result in positive outcomes, such as injecting fresh thoughts and stimulating the status-quo, voluntary employee turnover is generally considered undesirable and costly for organizations. These costs can include increased hiring and training expenses, learning curve inefficiencies and reduced customer satisfaction. Because organizations seek to reduce the negative economic impact caused by turnover, a greater understanding of the causes and organizational factors that influence it, such as job satisfaction, is warranted.

Recent studies have explored the influences on job satisfaction beyond basic compensation and promotional policies. In an attempt to better understand the antecedents of job satisfaction, empirical investigations have examined both individual as well as organizational factors. Studies have looked at whether job satisfaction is influenced by the level of communication with employees (Goris et al., 2000), the existence or perception of sexual harassment (Laband and Lentz, 1998) and whether employees are working with others who are of the same race (Moyes et al., 2000). Beginning in the 1990's a stream of research also began to explore the relationship between job satisfaction and organizational ethical constructs (e.g., Sims et al., 1994; Joseph and Deshpande, 1997; Koh and Boo, 2001; Valentine and Fleischman, 2004; Schwepker and Hartline, 2005; Mulki et al., 2006). The results of these ethics studies varied, and often took place within a narrowly defined context (single firm or single industry). In addition, the focal point of many of these job satisfaction/ethics studies has been in sales and marketing departments, where there is often pressure to directly produce revenue, and therefore more temptation to engage in unethical behavior. The recent accounting scandals have resulted in managers needing to be concerned with the ethical behavior of all employees, thereby creating a genuine need for broader research. The study presented here attempts to respond to these needs by empirically investigating, using a multiple firm/cross industry sample, whether an organization's ethical work climate, code of ethics, or ethical training has an impact on overall job satisfaction. This type of research is also relevant to managers because establishing and maintaining the components of an ethical program is the workplace is time consuming and expensive. If job satisfaction can be increased (and turnover conceivably decreased) as a result of certain aspects of these programs, then the investment of monetary resources towards this will produce an economic benefit.

\section{CONCEPTUAL FRAMEWORK}

\section{Does An Ethical Climate Actually Exist?}

Beginning as far back as the 1980 's, organizations were becoming increasingly interested in ethics and in establishing an environment in which ethical action would take place. The widespread interest was attributed to such factors as society's demand for broader corporate responsibility, regulatory and legal incentives, and financial motivations (Blodgett and Carlson, 1997; Daigneault, 1997; Dunafee and Werhane, 1997; Verschoor, 1997). In fact, Verschoor found that $84 \%$ of responding organizations had corporate policy pertaining to ethical behavior. In 1999, Morf et al. found that there was such broad concern for the issue that $75 \%$ of the companies surveyed actually incorporated ethical standards directly into their mission statements. Many organizations even went so far as to designate a specific employee as the "official" ethical officer. Yet whatever positive public perception these actions were generating, came to a screeching halt in 2002. Enron, WorldCom, Sunbeam, Tyco, to just name a few, became household names as the fraudulent accounting scandals and widespread corruption came to light. The broad extent of the unethical decision making was substantiated when a Brookings Institute analysis reported the United States economy lost $\$ 35$ billion dollars from the corporate scandals in just five months. It certainly appeared as though written corporate policy and assignment of ethical officers alone was not enough to truly influence individual employees to make ethical decisions. The Sarbanes-Oxley 2002 legislation imposed significantly stricter laws regulating acts of corporate fraud, including criminal liability for officers of the company. This provided an external source of motivation for employers to reexamine, and perhaps shift, their strategies for influencing individuals to make ethical decisions. Instead of merely focusing on compliance with written policy, organizations needed to 
employ a more in-depth examination to identify the factors or conditions that would effectively influence employees to make ethical workplace decisions.

The concept of influencing employee behavior is complex and involves many disciplines and paradigms. An extensive body of research has shown establishing an ethical environment within an organization involves multiple components, both those that are innate to the individual, as well as those that originate from within the organization. From within the organizational context, several early studies established the existence of corporate work climates (Schneider,1975) and corporate cultures (Schein, 1984). In 1987, Victor and Cullen extended Schneider's and Schein's assertions, and published groundbreaking research on ethical work climates, rooted on the principle that climates could be measured based on an individual's perceptions of organizational values and beliefs, and could be reported independent of how the individual feels about the environment. Their framework is based in the schools of philosophy, psychology and sociology, appropriately reflecting the complexity of organizational structure. Victor and Cullen's paradigm hypothesized that an organization will have one of five unique types of ethical climate, labeled instrumental, caring, independent, rules-oriented, laws and codes. They are distinguished from one another based on the criteria the organization emphasizes employees to consider when making a decision. For example, should the decision be guided based on existing rules or based on an attitude of caring and concern? Additional distinction is then made based on whether the rules or criteria for caring are self-established, company established, or more broad and societal.

In 1988 Victor and Cullen used their theoretical paradigm to develop a 26-item questionnaire, which when completed by employees, would identify which of the five types of ethical work climate exists within the organization. This questionnaire has held up to years of statistical scrutiny and is today, still considered a hallmark scale to identify an organization's ethical climate. It is used in this study to help determine if employees working in different types of ethical work climate experience more or less degrees of overall job satisfaction.

\section{Influencing Job Satisfaction}

Job satisfaction research is also rooted in substantial history, beginning with Pervin's 1968 work on individual-environmental fit. He looked at the ramifications to the organization if the atmosphere within that organization was not in congruence with an employee's individual disposition. Pervin's 1968 seminal work concluded a positive individual-environmental fit was important, stating, "a 'lack of fit' is viewed as resulting in decreased performance, dissatisfaction, and stress in the system" (p. 56). His work, suggesting organizational characteristics could be linked to employee satisfaction, was the basis for Victor and Cullen's (1988) specific proposition that ethical climate may play a role in influencing job satisfaction. Victor and Cullen's statement initiated a series of studies seeking to explore various aspects of their proposition/suggestion. Table 1 summarizes the context and conclusions of this empirical work. The majority of these results provide initial evidence that ethical climate and job satisfaction are related in service settings (i.e., hospitals, hotels, sales). The present study adds to this body of literature by sampling a broader representation of industries and utilizing a classically defined measure of ethical work climate.

\section{RESEARCH DESIGN}

\section{Hypotheses}

The specific hypotheses developed for this paper seek to build on the existing body of knowledge by using a larger sample than some of the prior studies and respondents representing a broad spectrum of organizations, both public and private, in the United States. Prior research provides evidence that ethics and job satisfaction are interrelated topics, and worthy of additional investigation. As a result of the recent corporate scandals, organizations are dedicating more resources to ethical programs. Additional understanding of potential benefits derived from these programs may be of practical benefit to an organization. The primary purpose of this study was to examine one such potential benefit: the impact on job satisfaction. Thus, the first hypothesis will identify each respondent's ethical work climate and then test the influence that particular climate has on job satisfaction.

$\mathbf{H}_{1}$ : An organization's perceived ethical work climate will influence job satisfaction. 
Table 1

Empirical Studies: Ethical Climate and Job Satisfaction

\begin{tabular}{|l|l|l|l|}
\hline Year & \multicolumn{1}{|c|}{ Author } & \multicolumn{1}{|c|}{ Setting } & \multicolumn{1}{c|}{ Conclusions } \\
\hline 1994 & Sims et al. & 66 individuals single hospital & $\begin{array}{l}\text { Work climate important variable in study of person- } \\
\text { organization fit (work environment matches personal } \\
\text { attributes) }\end{array}$ \\
\hline 1997 & Joseph \& Deshpande & Single, non-profit organization & $\begin{array}{l}\text { Managers may be able to influence job satisfaction by } \\
\text { influencing climate }\end{array}$ \\
\hline 2001 & Schwepker & Business to business salespeople & $\begin{array}{l}\text { Perception of "positive" ethical climate increases job } \\
\text { satisfaction }\end{array}$ \\
\hline 2001 & Koh \& Boo & MBA students, Singapore & $\begin{array}{l}\text { Employees working in a "principled" ethical climate } \\
\text { have higher job satisfaction }\end{array}$ \\
\hline 2005 & Schwepker \& Hartline & 3 hotels, service managers & $\begin{array}{l}\text { Perception of "positive" ethical climate increases job } \\
\text { satisfaction }\end{array}$ \\
\hline 2006 & Mulki et al. & Salespeople, single organization & $\begin{array}{l}\text { Trust in supervisor important element through which } \\
\text { ethical climate increases job satisfaction }\end{array}$ \\
\hline
\end{tabular}

Codes of ethics and ethical training programs are potential tools available for managers to help control the process of ethical decision making by employees. Creating an environment that fosters ethical outcomes is a benefit in and of itself, however, the programs require an investment of company resources and therefore managers should be aware of all potential benefits. There is the potential for a formal code of ethics and/or ethical training to influence how employees feel about their job. Ideally, adding ethical components to the corporate environment would enhance employees' job experience. Alternatively, they could view them as restrictive or time-wasting. Hypotheses two and three were developed to examine if having a code of ethics and ethical training would result in different levels of job satisfaction.

$\mathbf{H}_{2}$ : Employees at organizations with a code of ethics will report different levels of job satisfaction.

$\mathbf{H}_{3}$ : Employees of organizations that provide ethical training will report different levels of job satisfaction.

The primary statistical techniques used to conclude on the above hypotheses were ANOVA and correlation analysis. Statistical significance was evaluated based on the reported p-value. Descriptive statistics were used to further evaluate results generated from the data.

\section{Sample Selection}

The majority of prior research has selected samples from service industries and/or employees working in sales and marketing. Several recent studies have suggested that ethical climate research across industries is warranted (Weber and Seger, 2002, Schwepker and Hartline 2005). In order to broaden the scope of prior research studies, a purposive sample of students was drawn from five northeastern universities. Specifically, the sample consisted of undergraduate and graduate business students (from both public and private institutions), who were employed fulltime within the past six months. A voluntary in-class survey questionnaire was distributed to 291 individuals. After eliminating responses that did not meet the criteria for inclusion (not employed full time within the past six months) or were incomplete, 179 questionnaires remained and were included in the study. Relevant demographic data was collected in order to better describe the sample and gain a sense of the characteristics of the abstract population of fulltime employed business students. The frequency results indicate that respondents represent a variety of industries, ages, gender, and political preferences.

\section{Measurement Of Variables}

This study includes both continuous and discrete variables. An individual's perceived ethical work climate was measured using the five-scale instrument resulting from Victor and Cullen's 1988 work. A significant number of ethical work climate studies have used Victor and Cullen's ethical climate questionnaire While the majority of prior 
research used shorter, adapted versions of Victor and Cullen's scales, the current study uses their full and original questionnaire in order to statistically defend, and broaden the applicability of, any results. The remaining two independent variables, code of ethics and ethical training, were measured based on the respondent's direct answer (i.e., yes or no), and therefore are considered categorical data.

The dependent variable, job satisfaction, was measured with a six-item measure used by Curry et al. (1986) in their study of job satisfaction and organizational commitment. The index is an adaptation of Brayfield and Rothe's 18-item measure developed in 1951, which measures overall job satisfaction. Curry et al. used factor analysis to establish discriminant and convergent validity of the adapted measure. Subsequent studies provided further evidence of scale validity (Brooke et al., 1988; Nouri, 1992). Scale validity is an important indication that the answers to the questions being asked will actually result in measuring job satisfaction, and not something else. Internal consistency (ensuring the index is measuring job satisfaction consistently), was also established in the current study, yielding a Cronbach's alpha of .86 (Nunnally, 1978).

Response bias is a common problem in ethics research. Individuals, sensing the nature of the questions, may choose the answer they regard as being the most socially acceptable. The study reported on here, measured this response bias via a short form of the Marlowe-Crowne social desirability scale. Correlation analysis was applied to test for statistical significance between social desirability and each of the continuous variables (i.e., ethical work climate, job satisfaction). Neither variable tested significantly with social desirability; therefore, it was not considered to affect the statistical results.

Pre-existing scales to measure ethical work climate, job satisfaction, and social desirability were used in this study because they have established records of reliability and validity. The original instruments, with Likert response ranges, were combined on the questionnaire using discrete, stand alone sections in order to maintain the original format and scale independence. Cronbach's alpha ranged between .78 and .87 for each of the continuous variables (i.e., scales named caring, law and code, rules, instrumental, independence, and job satisfaction). These results, which were consistent with prior studies, indicate generally acceptable levels of construct internal consistency (Nunnally, 1978)

The questionnaire was pre-tested on an independent sample from the same population (i.e., full-time employed business students) to ensure the instructions and layout were clear and understandable. There were no problems noted and the questionnaire was distributed to the selected sample population.

\section{RESULTS}

As described above, this study hypothesized and tested the relationships between five categories of an independent variable (ethical work climate), two independent categorical variables, and the criterion variable, job satisfaction. Certain procedures were followed to help ensure any statistical results would be defendable. Initially, the scores from each Likert-like scale were combined to produce an index to allow for comparative analysis of scales containing different Likert characteristics (i.e., different scale ranges, such as 0-5 versus 1-5). The potential for muliticollinearity was also considered. If any of the five climates were too closely related it may interfere with explaining the relationship between a particular climate and job satisfaction. Two-tailed Pearson first-order partial correlation coefficients were calculated for the five ethical work climates to check for this. The results, which indicated some evidence of intercorrelations, were similar to other studies employing the Ethical Climate Questionnaire (e.g., Joseph and Deshpande, 1997; Argarwal and Malloy, 1999) and consistent with Victor and Cullen's $(1987,1988)$ theory that a dominant climate can still be isolated and measured even if climate interrelationships exist. 


\section{Does The Ethical Work Climate Influence Job Satisfaction?}

$\mathbf{H}_{1}$ : An organization's perceived ethical work climate will influence job satisfaction.

The results of this study indicated job satisfaction was impacted by the ethical climate of the employees' organization. In order to determine if a relationship existed between any of the measured ethical work climates and job satisfaction, correlation analysis was performed. The study did not presume that a particular ethical climate would either result in more or less job satisfaction, so a two- tailed Pearson's bivariate coefficient was the appropriate statistic to calculate. As Table 2 indicates, the analysis revealed significant relationships between job satisfaction and four of the five ethical climates. Stronger job satisfaction was found in climates where decisions are guided by benevolence and principled-thinking and specifically based on company procedures or societal norms. At the same time, individuals working in a climate where corporate self-interest is perceived, report lower levels of satisfaction.

Table2

Pearson's Bivariate Correlation Coefficients

\begin{tabular}{|c|c|c|c|c|c|}
\hline Ethical climate $\rightarrow$ & Caring & LawCode & Rules & Instrumental & Independent \\
\hline & \multicolumn{3}{|c|}{ Employees more satisfied } & $\begin{array}{c}\text { Employees less } \\
\text { satisfied }\end{array}$ & No correlation \\
\hline $\begin{array}{c}\text { JobSatisfac } \\
\text { (Correl) }\end{array}$ & .15 & .21 & .18 & -.22 & .12 \\
\hline Signif & .042 & .005 & .018 & .003 & .117 \\
\hline
\end{tabular}

Based on this initial evidence, additional testing was performed to gain further understanding of the suggestive relationships offered in Table 2. Correlation coefficients for job satisfaction and each respondent's maximum value for the five ethical work climates were calculated. A direct positive relationship was statistically supported and significant $(\mathrm{r}=.211, \mathrm{p}=.004)$. These results suggest that when climate characteristics are stronger, whichever climate is dominant, job satisfaction tends to be greater.

\section{Will A Code Of Ethics Make A Difference?}

$\mathbf{H}_{2}$ : Employees at organizations with a code of ethics will report different levels of job satisfaction.

This study did not find that employees of organizations with codes of ethics were more, or less, satisfied. Seventy-three percent of respondents indicated their organization had a code of ethics. In order to statistically test if the mean level of job satisfaction was different between the two populations, a one-way ANOVA test was run. The results were not significant $(\mathrm{F}=.390, \mathrm{p}=.533)$.

\section{Are There Benefits To Ethical Training?}

$\mathbf{H}_{3}$ : Employees of organizations that provide ethical training will report different levels of job satisfaction.

Thirty percent of full-time employed respondents indicated they had received ethical training from their current employer. These employees revealed a higher level of overall job satisfaction than the individuals who did not receive training. Initially, a one-way ANOVA was used to test whether having ethical training would result in a different level of job satisfaction. While the results did indicate a statistically significant difference between respondents $(\mathrm{F}=7.262, \mathrm{p}=.008)$, the ANOVA cannot explain the nature of the relationship (i.e., the direction of the difference). An evaluation of the descriptive statistics confirmed that employees who received ethical training reported higher levels of job satisfaction, than those who did not receive the training. 


\section{DISCUSSION}

This study revealed several interesting relationships between organizational ethical elements and job satisfaction. Ultimately, organizations are run by individuals, who make decisions and resolve conflicts on a daily basis. The recent accounting scandals have made it increasingly apparent that companies need to use whatever means possible to influence employees to make these decisions ethical ones. Studies have shown that for organizations to be effective in influencing their environment, the tone needs to be established at, and emanate from, the top. This creates quite a challenge to managers, who are often responsible for setting the tone in their departments. But what type of ethical tone to set, and are there other potential ramifications beyond influencing ethical workplace decisions? Victor and Cullen's widely respected model of organizational ethical climates $(1987,1988)$ identified five categories of ethical work climate, not presuming that one particular climate was good or bad. It would be up to the organization to determine if a particular environment was desirable or not, depending on the influence that environment was having on employees' behavior and attitudes, such as job satisfaction. The results of this study do not suggest that there is necessarily one 'best' climate. They do, however, establish that in the presence of certain climates job satisfaction was higher or lower. Practically speaking, employees were more satisfied in organizations where they perceived the ethical environment promoted by the company to be based on criteria established outside the confines of the firm's internal mechanism. Two potential tools available to help managers establish this employee perception are ethical training and a code of ethics. The present study also indicated that greater job satisfaction was achieved when employees received formal training, versus merely being aware of a corporate code of ethics. Therefore, managers who combine these two findings and promote an ethical environment based on societal norms and a caring undertone, via formal ethical training, are most likely to optimize employee job satisfaction.

Even if a manager does not have the ability to significantly influence or "shift" their department's ethical climate, this study also revealed another strategy for using the ethical environment to improve job satisfaction. Statistical analysis indicated that when employees have a stronger and clearer sense of the organization's ethical position they experience greater overall job satisfaction. Again, formal training is a means to increase employee awareness of the job related ethical expectations.

Many resources exist to aide in providing training to employees. With the availability of advanced technology, the delivery of this training can take on many forms, providing optimal flexibility and customization to managers. Table 3 is a summary of available resources.

\section{CONCLUSION}

The findings from the current study should encourage managers and organizations to invest resources into actively managing their ethical climate. Ethical training, reinforcement of the company's ethical position, and establishing that position as more altruistic versus self-serving, all resulted in greater job satisfaction. Although increased job satisfaction is traditionally considered a non-monetary benefit, the reduced turnover costs resulting from it provide a tangible and measurable benefit, thus providing a return to the organization for their investment in the process of influencing and managing organizational ethics.

\section{RECOMMENDATIONS FOR FUTURE RESEARCH}

The study reported on here provides points to a basic relationship between ethical training and job satisfaction. Future studies should consider expanding the breadth of each of these variables in order to more narrowly determine the types of ethical training which are related to particular aspects of job satisfaction. 
Table 3

Business Ethical Resources

\begin{tabular}{|l|l|l|}
\hline \multicolumn{1}{|c|}{ Organization } & \multicolumn{1}{|c|}{ Contact } & \multicolumn{1}{c|}{ Resources } \\
\hline Ethics Resource Center & www.ethics.org & $\begin{array}{l}\text { Non-profit educational center devoted to } \\
\text { organizational ethics. Sponsors the } \\
\text { annual National Business Ethics Survey }\end{array}$ \\
\hline $\begin{array}{l}\text { Center for Ethical Business } \\
\text { Cultures }\end{array}$ & www.cebcglobal.org & $\begin{array}{l}\text { Independent, non-profit organization } \\
\text { with resources to assist managers }\end{array}$ \\
\hline $\begin{array}{l}\text { Association for Practical and } \\
\text { Professional Ethics }\end{array}$ & www.indiana.edu/\%7eappe & $\begin{array}{l}\text { University funded. Resources available } \\
\text { for practitioners, scholars and educators. }\end{array}$ \\
\hline Society for Business Ethics & www.societyforbusinessethics.org & $\begin{array}{l}\text { International association open to } \\
\text { academics and professionals } \\
\text { specializing in business ethics }\end{array}$ \\
\hline $\begin{array}{l}\text { Society for Human Resource } \\
\text { Management }\end{array}$ & www.shrm.org/foundation & $\begin{array}{l}\text { SHRM “foundation products" and "HR } \\
\text { bookstore" offer DVD case study } \\
\text { training and other tools }\end{array}$ \\
\hline $\begin{array}{l}\text { Ethical \& Compliance Officer } \\
\text { Association }\end{array}$ & www.theecoa.org & $\begin{array}{l}\text { Professional association for managers } \\
\text { responsible for their company's ethics } \\
\text { programs }\end{array}$ \\
\hline
\end{tabular}

The results of this study also revealed a relationship between certain types of ethical climate and job satisfaction, but measuring and understanding the complete corporate ethical construct is complex. When employees are hired they bring their own set of individual ethical characteristics, creating the potential for incongruence between the ethical work climate and an individual's ethical beliefs. Future research should consider examining the influence organizational ethical work climate has on moderating these individual characteristics with regards to employee behavior and satisfaction.

\section{LIMITATIONS}

Certain limitations affect this research. Perhaps the most significant is the use of an abstract construct to measure an individual's perception of a dominant ethical work climate. Although an abundance of literature supports the existence of an ethical climate as a distinct and separate contextual organizational factor, from a theoretical perspective, it remains controversial.

In addition, the data for this study was gathered by asking respondents to self-report on sensitive topics (i.e., ethics, job satisfaction). Although the study attempted to measure this effect, it's possible that inherent response-bias impacted the results. Also, certain scales were modified slightly for context, and post-hoc tests could not be performed to further investigate the job training relevance because there were fewer than three populations (employees only indicated a "yes" or "no").

\section{REFERENCES}

1. Agarwal, J. and D. C. Malloy: 1999, 'Ethical Work Climate Dimensions in a Not-for-Profit Organization', Journal of Business Ethics 20(1), 1-14.

2. Blodgett, M. and P. Carlson: 1997, 'Corporate Ethics Codes: A Practical Application of Liability Prevention', Journal of Business Ethics 16(12), 1363-1369.

3. Brooke, P. P., D. W. Russell and J. L. Price: 1988, 'Discriminant Validation of Measures of Job Satisfaction, Job Involvement, and Organizational Commitment', Journal of Applied Psychology 73(2), 139-145.

4. $\quad$ Curry, J. P., D. S. Wakefield, J. L. Price and C. W. Mueller: 1986, 'On the Causal Ordering of Job Satisfaction and Organizational Commitment', Academy of Management Journal 29(4), 847-858.

5. $\quad$ Daigneault, M. G.: 1997, 'Why Ethics?', Association Management 49(9), $28-34$.

6. Dunafee, T. and P. Werhane: 1997, 'Report on Business Ethics in North America', Journal of Business Ethics 16(14), 1589-1595. 
7. Eby, L. T., D. M. Freeman, M. C. Rush and C. E. Lance: 1999, 'Motivational Bases of Affective Organizational Commitment: A Partial Test of an Integrative Theoretical Model', Journal of Occupational and Organizational Psychology 72(4), 463-483.

8. Eyewitness News (2006, March 21). New York, NY: American Broadcasting Company.

9. Goris, J. R., B. C. Vaught and J. D. Pettit: 2000, 'Effects of Communication Direction on Job Performance and Satisfaction: A Moderated Regression Analysis', Journal of Business Communication 37(4), 348-368.

10. Herndon, N. C., J. P. Fraedrich and Q. J. Yeh: 2001, 'An Investigation of Moral Values and the Ethical Content of the Corporate Culture: Taiwanese Versus U. S. Sales People', Journal of Business Ethics 30(1), 73-85.

11. Joseph, J. and S. P. Deshpande: 1997, 'The Impact of Ethical Climate on Job Satisfaction of Nurses', Health Care Management Review 22(1), 76-81.

12. Koh, H. C. and E. H. Y. Boo: 2001, 'The Link between Organizational Ethics and Job Satisfaction: A Study of Managers in Singapore', Journal of Business Ethics 29(4), 265-271.

13. Laband, D. N. and B. F. Lentz: 1998, 'The Effects of Sexual Harassment on Job Satisfaction, Earnings, and Turnover Among Female Lawyers', Industrial \& Labor Relations Review 51(4), 594-607.

14. Larwood, L., T. A. Wright, S. Desrochers and V. Dahir: 1998, 'Extending Latent Role and Psychological Contract Theories to Predict Intent to Turnover and Politics in Business Organizations', Group \& Organization Management 23(2), 100-123.

15. Morf, D. A., M. G. Schumacher and S. J. Vitell: 1999, 'A Survey of Ethical Officers in Large Organizations', Journal of Business Ethics 20(3), 265-271.

16. Moyes, G. D., P. A. Williams and B. Z. Quigley: 2000, 'The Relation between Perceived Treatment Discrimination and Job Satisfaction Among African-American Accounting Professionals', Accounting Horizons 14(1), 21-48.

17. Mulki, J. P. , F. J. Jaramillo and W. B. Locander: 2006, 'Effects of Ethical Climate and Supervisory Trust on Salesperson's Job Attitudes and Intentions to Quit', Journla of Personal Selling and Sales Management 26(1), 19-26.

18. Nouri, H.: 1992, 'The Effect of Budgetary Participation on Job Performance: A Conceptual Model and its Empirical Test', Unpublished doctoral dissertation, Temple University, Philadelphia, PA.

19. Nunnally, J. C.: 1978, Psychometric Theory, $2^{\text {nd }}$ edition (McGraw-Hill Book Company, New York).

20. Pervin, L. A.: 1968, 'Performance and Satisfaction as a Function of Individual Fit', Psychological Bulletin 69(1), 56-68.

21. Schein, E. H.: 1984, 'Coming to a New Awareness of Organizational Culture', Sloan Management Review 25, 3-16.

22. Schneider, B.: 1975, 'Organizational Climate: An Essay’, Personnel Psychology 28, 447-479.

23. Schwepker, C. H. Jr.: 2001, 'Ethical Climate's Relationship to Job Satisfaction, Organizational Commitment, and Turnover Intention in the Salesforce', Journal of Business Research 54(1), 39-52.

24. Schwepker, C. H. and M. D. Hartline: 2005, 'Managing the Ethical Climate of Cusomer -Contact Service Employees', Journal of Service Research 7(4), 377-397.

25. Sims, R. L., K. G. Kroeck and K. Galen: 1994, 'The Influence of Ethical Fit on Employee Satisfaction, Commitment, and Turnover', Journal of Business Ethics 13(12), 939-947.

26. Valentine, S. and G. Fleischman: 2004, 'Ethics Training and Businesspersons' Perceptions of Organizational Ethics', Journal of Business Ethics 52(4), 381-390.

27. Verschoor, C.: 1997, 'Principles Build Profits', Management Accounting 79(4), 42-46.

28. Victor, B. and J. B. Cullen: 1987, 'A Theory and Measure of Ethical Climate in Organizations', in W. C. Frederick (ed.), Research in Corporate Social Performance and Policy (JAI Press Inc., Greenwich, CT), pp. 51-71.

29. Victor, B. and J. B. Cullen: 1988, 'The Organizational Bases of Ethical Work Climates', Administrative Science Quarterly 33(1), 101-125.

30. Weber, J. and J. E. Seger: 2002, 'Influences Upon Organizational Ethical Subclimates: A Replication Study of a Single Firm at Two Points in Time', Journal of Business Ethics 41(1/2 ), 69-84. 


\section{NOTES}

